\title{
IMPLEMENTING LOW COST DIGITAL LIBRARIES FOR RURAL COMMUNITIES BY RE-FUNCTIONING OBSOLESCENT TELEVISION SETS
}

\section{THE OFFLINE-PEDIA PROJECT}

\author{
Sergio Minniti \\ University of Padova \\ Department of Philosophy, Sociology, Education and Applied Psychology (FISPPA) \\ Via Cesarotti 10/12 \\ 35123 Padova \\ Italy \\ sergio.minniti@unipd.it \\ Joshua Salazar \\ Yachay Tech University \\ School of Physical Sciences and Nanotechnology \\ Hacienda San José s/n, Vía a Yachay \\ San Miguel de Urcuquí, 100115 \\ Ecuador \\ joshua.salazar@yachaytech.edu.ec \\ Jorge Vega \\ Yachay Tech University \\ School of Physical Sciences and Nanotechnology \\ Hacienda San José s/n, Vía a Yachay \\ San Miguel de Urcuquí, 100115 \\ Ecuador \\ jorge.vega@yachaytech.edu.ec
}

\begin{abstract}
The article addresses the issue of the digital divide in Ecuador and illustrates how artefacts from television material heritage might be transformed into digital libraries to provide marginalized communities with access to digital information. It describes an ongoing socio-technical project which aims at providing Ecuadorian rural communities with access to digital information through the re-functioning of analogue TV sets and other complementary technologies that will become obsolete due to Ecuador's switch from an analogue to digital broadcasting signal. On one hand, the project is discussed with reference to the contemporary debate in the fields of Media and Television Studies on the obsolescence and renewal of technology; And on the other, it is discussed on the background of earlier projects focusing on the design of digital libraries to circulate information and improve digital literacy in rural contexts. Finally, the prototype created is discussed from a technical and conceptual point of view.
\end{abstract}

Keywords: digital divide, Ecuador, renewability of media, cosmolocalism, critical technical practice 
S. Minniti et al., Implementing Low Cost Digital Libraries for Rural Communities by Re-functioning Obsolescent Television Sets

\section{Introduction}

It is widely acknowledged that information and communications technology (ICT), which is firmly entrenched in the everyday lives of billions of people, underpins the social and economic progression of nation-states, transforming countries into "knowledge economies" and "network societies." However, the "techno-enthusiasm" that has accompanied the spreading of ICT, together with a widespread and uncritical understanding of ICT's transformative effect as an intrinsically positive movement towards the "empowerment" of individuals ${ }^{2}$ and the increase of social interaction and civic participation, ${ }^{3}$ has been substantially tempered by concerns over the divisive aspects of the information age, and especially by concerns over the inequalities deriving from critical infrastructural differences across the globe in terms of access to both technology and information. ${ }^{4}$

Such issues of inequality have begun to prompt concern about emerging "digital divides" between social groups, urban and rural zones, as well as between developed and developing countries. ${ }^{5}$ In this respect, it is important to point out how the concept of "digital divide," which was initially and simplistically defined as the invisible border that separates those who have access to ICTs and those who have not, has been further problematized beyond the exclusive consideration of the technological dimension, and accordingly broadened to include the complexity and meaningfulness of socio-technical life: "What is most important about ICTs is not so much the availability of the computing device or the Internet line, but rather people's ability to make use of that device and line to engage in meaningful social practices." 6

The notion of "digital divide" has thus been rethought and stretched to encompass a broad array of factors and resources that allow people to use ICT for meaningful ends, including not only the physical availability of computers and connectivity, but also issues of content, language, education, literacy, community and social resources. ${ }^{7}$ As a result of this revision of the notion of "digital divide", more scholarly attention has been paid to the historical and socio-cultural circumstances within which ICTs and information resources acquire meaning, in order to understand how ICTs actually work in contexts such as those of developing countries, where the a-contextual and universalistic discourse of ICT and development, and the accompanying simplistic distinction between the "information rich" and "information poor," inevitably limits our sociological understanding of the situated practices through which ICTs, knowledge, and information become meaningful. Put simply, this line of enquiry requires us to critically consider "the extent to which the information society conveys aspirations, and privilege technologies, information and knowledge that are irrelevant to the way the majority of people in many communities in developing countries live their lives". 8

1 Manuel Castells, The Information Age: Economy, Society and Culture. Volume I - The Rise of the Network Society, Blackwell, 1996.

2 Donna M. D'Alessandro and Nienke P. Dosa, 'Empowering Children and Families with Information Technology,' Archives of Paediatric \& Adolescent Medicine, 155, 10, 2001, 1131-1136.

3 James E. Katz, Ronald E. Rice and Philip Aspden, 'The Internet 1995-2000: Access, Civic Involvement and Social Interaction,' American Behavioural Scientist, 45, 3, 2001, 405-419.

4 Neil Selwyn, 'Reconsidering Political and Popular Understandings of the Digital Divide,' New Media \& Society, 6, 3, $2004,341-362$.

5 Allam Ahmed, 'Making Technology Work for the Poor: Strategies and Policies for African Sustainable Development,' International Journal of Technology, Policy and Management, 4, 1, 2004, 1-17; Allam Ahmed, ed, World Sustainable Development Outlook 2007: Knowledge Management and Sustainable Development in the $21^{\text {st }}$ Century, Routledge, 2017.

6 Mark Warschauer, 'Reconceptualizing the Digital Divide,' First Monday, 7, 7, 2002, http://uncommonculture.org/ojs/index.php/fm/article/ view/967/888

7 Paul DiMaggio, Eszter Hargittai, W. Russell Neuman and John P. Robinson, 'Social Implications of the Internet,' Annual Review of Sociology, 27, 2001, 307-336; David J. Gunkel, 'Second Thoughts: Toward a Critique of the Digital Divide', New Media \& Society, 5, 4, 2003, 499-522; Neil Selwyn, 'Reconsidering Political and Popular Understandings of the Digital Divide,' New Media \& Society, 6, 3, $2004,341-362$.

8 Chrisanthi Avgerou and Shirin Madon, 'Information Society and the Digital Divide Problem in Developing Countries,' in Jacques Berleur and Chrisanthi Avgerou, eds, Perspectives and Policies on ICT in Society, Springer, 2005, 205-217. 
S. Minniti et al., Implementing Low Cost Digital Libraries for Rural Communities by Re-functioning Obsolescent Television Sets

The recognizing of the mediating role of economic, cultural, and social dynamics in shaping the individuals' engagements with ICT, it not only allows the development of more sociologically sophisticated accounts of the relationship between ICTs and society, but it also provides governments and institutions with richer roadmaps for using technology to promote social development and inclusion.

In this article, we draw on such reflections concerning the "digital divide" and describe a project we are carrying out in Ecuador, called Offline-pedia, which addresses issues related to how television's material heritage can be revived by transforming obsolescent TV sets and other pieces of technology into digital libraries that allow people from Ecuadorian rural communities to overcome the limits of dominant ICT infrastructures, have access digital information, and use it to pursue their meaningful ends.

\section{ICT Development in Ecuador}

The Republic of Ecuador is located in the Andean region of South America. Its population, made up of a variety of ethnic groups, was estimated in 2015 at $16,144,368 .{ }^{9}$ Ecuador is a large producer of bananas and oil, with oil contributing around one-third of the government revenue, comprising $20 \%$ of the economy and $45 \%$ of exports. ${ }^{10}$ Nevertheless, Ecuador remains one of the poorest countries in South America, with a low GDP per capita and large segments of the population in the condition of extreme poverty. ${ }^{11}$ In the 1990 s, Ecuador has experienced political instability, coups d'état, high inflation, "dollarisation," and low growth. ${ }^{12}$ It has achieved some economic and political stability in the last decades, especially during the Presidency of Rafael Correa (2007-2017). ${ }^{13}$ According to the Central Bank of Ecuador, ${ }^{14}$ economic indicators show a positive trend during the period 2008-2018, notwithstanding a recession started in 2015, which was caused mainly by natural disasters and Ecuador's reliance on oil. ${ }^{15}$ On the other hand, Correa's government also increased the country's deficit, ${ }^{16}$ and the cost of corruption in the public sector remained high during the decade. ${ }^{17}$

Before the election of President Correa and the establishment of the National Plan for Good Living (Plan Nacional para el Buen Vivir), ${ }^{18}$ ICT development had not been a priority of policy makers, and this is still reflected in Ecuador's low rankings in the Networked Readiness Index ${ }^{19}$ and EIU Digital Economy Ranking. ${ }^{20}$ Ecuador's ICTs

9 Data gathered from United Nations' World Population Prospects 2017, https:/lesa.un.org/unpd/wpp/DataQuery/

10 The Economist, 'Free-for-oil,' The Economist, 376, 8441, 25 August 2005, 33.

11 Carlo Figa Talamanca, Aleardo Furlani and Alex Da Silve Alves, ICT Cluster Priority Assessment ICT and SMEs: A Strategy Framework for the Development of the Latin American and Caribbean Region, Inter-American Development Bank, 2006.

12 Nader Nazmi, 'Failed Reforms and Economic Collapse in Ecuador,' The Quarterly Review of Economics and Finance, 41, 5, 2001, 727-735.

13 Vicente Fretes-Cibils, Marcelo Giugale, Eduardo Somensatto, eds, Revisiting Ecuador's Economic and Social Agenda in an Evolving Landscape, The International Bank for Reconstruction and Development/The World Bank, 2008.

14 Banca Central del Ecuador, 'Cartilla trimestral e indicador mensual de actividad económica No. 25,' 2018, https://www.bce.fin.ec/index.php/ component/k2/item/313-indice-de-actividad-econ\%C3\%B3mica-coyuntural-ideac

15 Andres Oppenheimer, 'Correa's 'Economic Miracle' in Ecuador Was Actually a Monumental Sham,' Miami Herald, 3 March 2017, http://www. miamiherald.com/news/local/news-columns-blogs/andres-oppenheimer/article136054198.html

16 El Universo, 'A Lenín Moreno le toca pagar 'consumo' de una mesa que no estaba 'servida', 'El Universo, 16 July 2017, https://www. eluniverso.com/noticias/2017/07/16/nota/6281869/moreno-le-toca-pagar-consumo-mesa-que-no-estaba-servida

17 El Universo, 'Más de \$ 35 mil millones se estima perjuicio al país,' El Universo, 14 December 2017, https://www.eluniverso.com/ noticias/2017/12/14/nota/6525505/mas-35-mil-millones-se-estima-perjuicio-pais

18 http://www.buenvivir.gob.ec/versiones-plan-nacional;jsessionid=42A5F1CF81C2699FE73F5AC91C400A56

19 Silja Baller, Soumitra Dutta and Bruno Lanvin, eds, The Global Information Technology Report 2016: Innovating in the Digital Economy, World Economic Forum and INSEAD, 2016, http://www3.weforum.org/docs/GITR2016/WEF_GITR_Full_Report.pdf

20 Economist Intelligence Unit, Digital Economy Rankings 2010: Beyond E-readiness, The Economist Intelligence Unit Limited, 2010, http:// graphics.eiu.com/upload/EIU_Digital_economy_rankings_2010_FINAL_WEB.pdf 
infrastructure has often been described as underdeveloped and expensive. ${ }^{21}$ On the one hand progresses has occurred, yet on the other hand large segments of the population are still unable to take full advantage of the benefits provided by the digital revolution.

According to The Global Information Technology Report, 22 in 2016 the percentage of individuals using the Internet amounted to $43 \%$; the percentage of households with personal computers was $38 \%$; and the percentage of households with Internet access was 32\%. In its report on the status of ICTs in Ecuador in 2016, ${ }^{23}$ the INEC (Instituto Nacional de Estadistica y Censos) signals an increase of $13.7 \%$ of the households with mobile computers between 2012 and 2016, and a substantially stable percentage of households with desktop computers, percentages which in 2016 accounted respectively for the $27.6 \%$ and $26.7 \%$ of the households included in the sample. The percentage of households with at least one mobile phone has increased by $8.4 \%$ in the same period, and in 2016 it accounted for the $90.1 \%$ of the sampled households, while the percentage of households with a fixed phone has decreased from $42.4 \%$ to $38.4 \%$.

At the national level, households with access to the Internet have incremented from $22.5 \%$ in 2012 to $36 \%$ in 2016 . Yet, the urban and rural zones of the country present significantly different values, which testify to the existence of an urban-rural digital divide. As a matter of fact, during the five years analysed by INAC, access to the Internet in the urban zones has increased from $31.4 \%$ to $44.6 \%$, while in the rural zones it has increased from $4.8 \%$ to $16.4 \%$. The urban-rural divide is also reflected in the percentage of people using computers, which in the urban zones amounted to $59.5 \%$ in 2016 , while in the rural zones it reached $37.3 \%$. Similarly, the percentage of people who live in urban zones and use the Internet amounted to $63.8 \%$ in 2016 , while in the rural zones the percentage reached only $38 \%$. INAC also reports a difference in terms of points of access to the Internet: in the urban zones, the household is the most diffused point of access $(59.5 \%)$, while in the rural zones people access the Internet mainly from public access points $(36.8 \%)$. When considering the rate of digital analphabetism, INAC reports that the percentage of digital illiterates decreased from $21.4 \%$ to $11.5 \%$ in the period $2012-2016$, yet digital analphabetism is more present in the rural zones of the country, where $22 \%$ of the inhabitants were digital illiterates in 2016 , while in the urban zones this percentage amounted to $6.9 \%$ in the same year.

Statistics show therefore, that the ICT sector in Ecuador still has considerable potential for development. The Government, along with market players, has dedicated efforts to infrastructure development and public policies to bridge the digital divide. The Ecuadorian Government recently launched the National Plan for Telecommunications and Information and Communication Technologies 2016-2021 (Plan Nacional de Telecomunicaciones y Tecnologías de Información y Comunicación 2016-2021), ${ }^{24}$ which focuses on infrastructure development and the increase of ICT penetration rates. Another important programme, the National Plan for Good Living 2013-2017,25 explicitly aims at democratizing access to telecommunications services and increasing digital literacy among the Ecuadorian population.

\section{The Offline-pedia Project}

Offline-pedia is a device designed to function as a rural digital library nucleus (Figure 1). It makes selected digital collections, such as Wikipedia and Wikibooks, accessible in contexts where access to the Internet is limited or

\footnotetext{
21 Stan Karanasios, 'Ecuador, the Digital Divide and Small Tourism Enterprises,' Journal of Business systems, Governance and Ethics, 2, 3, 2007, 21-34.

22 Silja Baller, Soumitra Dutta and Bruno Lanvin, The Global Information Technology Report 2016, p. 89.

23 INEC, Tecnologías de la Información y Comunicaciones (TIC'S), 2016, http://www.ecuadorencifras.gob.ec/documentos/web-inec/ Estadisticas_Sociales/TIC/2016/170125.Presentacion_Tics_2016.pdf

24 https://www.telecomunicaciones.gob.ec/wp-content/uploads/2016/08/Plan-de-Telecomunicaciones-y-TI..pdf

25 http://www.buenvivir.gob.ec/versiones-plan-nacional;jsessionid=42A5F1CF81C2699FE73F5AC91C400A56\#tabs1
} 
unavailable, as is the case of Ecuadorian rural communities. The main objective of the project is that of overcoming the digital divide by "re-materializing" digital information, that is, by separating it from its main distribution media through the design of a physical device that can be accessed without any connection to the Internet. The secondary objective of the project is that of illustrating how obsolescent technologies can be renewed and transformed into useful resources instead of becoming electronic waste. In the case of Offline-pedia, both objectives are accomplished by "re-functioning" the television equipment that will become obsolete due to Ecuador's switch from an analogue to digital broadcasting signal, which is planned to occur between 2020 and 2023.

In the following sections, we first review pre-existing projects focusing on digital libraries specifically designed for disadvantaged and rural communities, and identify an increasing trend towards the adoption of offline solutions (section 3.1). We then discuss issues relating to the obsolescence and renewal of technology with reference to the contemporary debate on the subject in the fields of Media and Television Studies (section 3.2). Finally, we discuss the Offline-pedia project from a conceptual and technical point of view, and illustrate its current status as well as its future implementations (section 3.3).

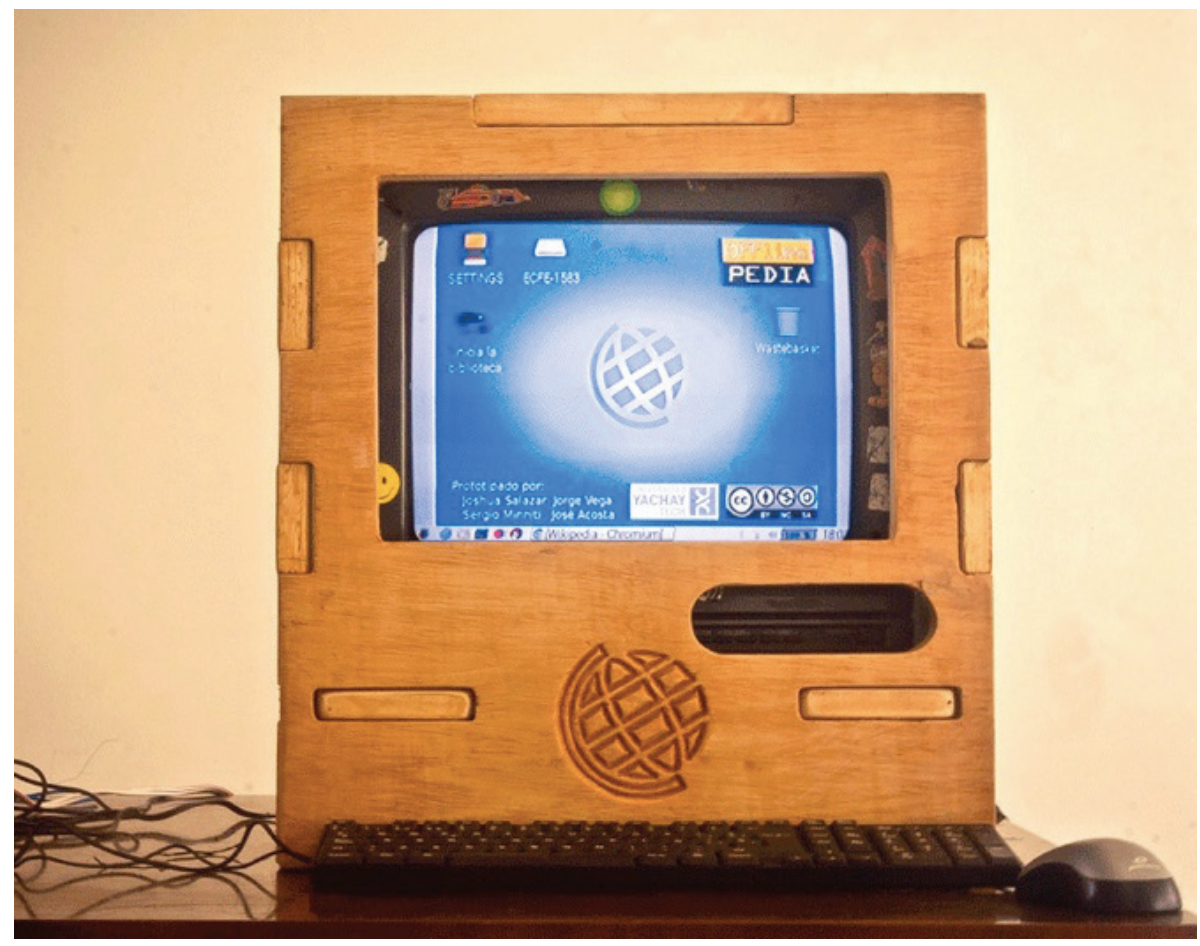

Figure 1. The first prototype of the rural digital library Offline-pedia. Photo by the authors.

\subsection{Rural Digital Libraries: From Bandwidth to Storewidth}

Projects addressing the digital divide in developing countries have flourished over the course of the last 20 years. Among them, we find several projects focusing on the design of affordable Digital Libraries (DLs) as a practical solution to deliver "a wealth of knowledge without requiring a wealth of investment" 26 in contexts 
where access to the Internet is limited or unavailable, with the explicit aim of "bridging the gap" represented by the digital divide. ${ }^{27}$

The very basic idea of adopting DLs for the benefit of the developing world, compensating for the failure of mainstream information distribution mechanisms, and with an emphasis on the cultural and humanitarian applications of delivering information where it is needed more, can be dated back to the seminal work of a team of researchers from the University of Waikato, New Zealand. Led by lan Witten, in 1997 the research group initiated the development of the Greenstone Digital Library Software, ${ }^{28}$ an open source suite of software tools for building and disseminating DLs, distributed freely via SourceForge since November 2000.

Broadly defined as organized "collections of digital objects, including text, video, and audio, along with methods for access and retrieval, and for selection, organization, and maintenance, ${ }^{\prime 29}$ DLs were conceived by the group as fundamental for the effective development and empowerment of underprivileged countries. According to Witten and his collaborators, DLs could be used to serve a series of purposes that were thought to be particularly important in developing countries: disseminating humanitarian information; preserving indigenous cultures; and storing locally produced information addressing specific needs and community issues. ${ }^{30}$ The humanitarian orientation of the project was reflected by the fact that its development was sponsored by the UNESCO, and informed by the experience of non-governmental organizations (NGOs) and United Nations agencies in facilitating the dissemination of humanitarian information for the benefit of the developing world. ${ }^{31}$

It is worth noting that Greenstone is not a DL, but rather a tool for building DLs and collections - as the authors point out, digital collections are assortments of documents with a uniform interface through which documents can be accessed, while DLs include a number of different collections, each organized differently. ${ }^{32}$ Apart from providing a new way of organizing information, Greenstone offers easy-to-use tools for publishing it on the Internet in the form of fully-searchable, metadata-driven collections and libraries. Since most DLs are accessed via the Internet, the Greenstone's interface uses a web browser. However, since in many developing countries Internet access is not pervasive enough, Greenstone's developers have also provided the users with the possibility of adopting offline solutions. After a few years of experimentation, they started proposing to separate the structure and organization of DLs from their distribution media, by both developing a web serving software that could be used locally on standalone machines, and promoting the physical dissemination of information on recordable devices such as CD-ROMs and DVDs as a viable alternative to its online circulation. ${ }^{33}$ Later on, they also developed a Portable Digital Library on the iPod, a self-contained DL created by adapting Greenstone to the iPod-Linux operating system. ${ }^{34}$

In the following years, the ideas sketched above have been improved by following two main directions: on the one hand, the role of DLs has been acknowledged as particularly important in rural contexts, leading to the definition of the concept of Rural Digital Library (RDL); on the other hand, projects addressing the issue of digital divide through the development of DLs have increasingly switched from online to offline solutions. Exemplary of the former is the

27 Gobinda G. Chowdhury, 'Digital Divide: How Can Digital Libraries Bridge the Gap?,' in Ee-Peng Lim, Schubert Foo, Chris Khoo, Hsinchun Chen, Edward Fox, Shalini Urs and Thanos Costantino, eds, Digital Libraries: People, Knowledge, and Technology, Springer, 2002, 379-391.

28 http://www.greenstone.org/

29 Ian H. Witten and David Bainbridge, How to Build a Digital Library, Morgan Kaufmann, 2003, p. XXVI.

30 Ibid., pp. 20-24.

31 lan H. Witten and David Bainbridge, 'The Greenstone Digital Library Software,' in Yin-Leng Theng, Schubert Foo, Dion Goh and Jin-Cheon Na, eds, Handbook of Research on Digital Libraries: Design, Development, and Impact, Information Science Reference, 2009, 61-72.

32 Ian H. Witten and David Bainbridge, How to Build a Digital Library, pp. 25-26.

33 Ibid., pp. 23-24.

34 David Bainbridge, Steve Jones, Sam Mclntosh, Matt Jones and lan H. Witten (2008) 'Portable Digital Libraries on an iPod,' in Proceedings of the $8^{\text {th }}$ ACM/IEEE Joint Conference on Digital Libraries (JCDL'08), ACM, 2008, 333-336. 
S. Minniti et al., Implementing Low Cost Digital Libraries for Rural Communities by Re-functioning Obsolescent Television Sets

proposal of developing RDLs in Nepal, creating a community-owned library system for rural development, with the aim of empowering local communities and help them benefit from access to global information. ${ }^{35}$

Similarly, DLs have been included in the Digital Doorway project, ${ }^{36}$ a joint initiative developed in South Africa by the Department of Science and Technology (DST), the Department of Rural Development and Land Reform (DRDL), and the Council for Scientific and Industrial Research (CSIR). Aiming at introducing computer literacy and providing people in rural areas with freely accessible digital equipment, open source software, and educational information, Digital Doorway involves the installation of multi-terminal computer systems in the form of both free-standing kiosks and solar-powered containers. ${ }^{37}$ The units thus serve as both tools for computer literacy development and as DLs. While the containers also provide Internet connectivity and Wi-Fi access points, the kiosks are designed as standalone machines to be used as offline versions of the Digital Doorway.

The interest in developing offline DLs specifically designed to work in rural contexts has increased during the 2000s, and is reflected in a number of projects. Among the most notable examples we find the eGranary Digital Library (also dubbed "The Internet in a Box"), ${ }^{38}$ with 1200 units installed in more than 50 countries globally, most of which are located in Sub-Saharan Africa. Developed by the staff of the University of lowa's WiderNet Project, eGranary is a plug-and-play storage technology which provides access to millions of digital educational documents without the need of a connection to the Internet, and is conceived as a technologically appropriate and "low-cost way to deliver knowledge to the world's information poor." ${ }^{\text {29 }}$

A more recent example is SolarSPELL (Solar Powered Educational Learning Library), ${ }^{40}$ a solar-powered offline DL developed at the Arizona State University. SolarSPELL DLs complement open-access resources on a variety of topics with locally-relevant content, and provide the opportunity to both retrieve information and develop technological literacy in regions lacking access to the Internet and electricity. The project was initiated in 2015, and to date it has deployed over 200 DLs across the Pacific Islands, as well as some African countries. ${ }^{41}$

In carrying out our project, we took into account the evolution of DLs from Internet-based to stand-alone devices, thus adopting the latter solution with the aim of making Offline-pedia suitable to be used by the rural communities of Ecuador, where access to the Internet is very limited.

\subsection{The Obsolescence and Renewal of Media Technologies}

Over the last fifteen years, we have witnessed a significant re-appropriation of media technologies from the past, which has attracted both scholarly and popular interest. Among the most notable examples we find vinyl records, ${ }^{42}$

35 Binod Vaidya and Jagan Nath Shrestha, 'Rural Digital Library: Connecting Rural Communities in Nepal,' in Ee-Peng Lim et al., Digital Libraries, pp. 354-365.

36 http://www.digitaldoorway.org.za/index_main.php

37 Elizabeth Greyling and Ronel Smith, 'An Innovative ICT Solution to Steer Rural Communities to Global Understanding: A Case Study from Durban, South Africa,' in Proceedings of the 74th IFLA WLIC General Conference, 2008, http://archive.ifla.org/IV/ifla74/papers/109-Greyling_ Smith-en.pdf

38 http://www.widernet.org/eGranary/

39 Cliff Missen, 'Internet in a Box,' p. 193

40 http://solarspell.org/

41 Kristen Linzy and Laura Hosman, 'The SolarSPELL Offline Digital Library,' in Proceedings of the 84th IFLA WLIC General Conference, 2018. http://library.ifla.org/2106/1/205-linzy-en.pdf

42 Dominik Bartmanski and lan Woodward, Vinyl: The Analogue Record in the Digital Age, Bloomsbury, 2015. 
S. Minniti et al., Implementing Low Cost Digital Libraries for Rural Communities by Re-functioning Obsolescent Television Sets

Polaroid cameras and films, ${ }^{43}$ but also early digital devices such as the obsolete computers used by "retrocomputing" enthusiasts, ${ }^{44}$ and even the once-obsolete brick mobile phones, newly touted as the "dumb phones" that provide the very basic functionality of making calls. ${ }^{45}$

Analyses of these phenomena, variously labelled as "retromedia"46 or "retrotechnologies," ${ }^{37}$ have had the potential to refashion scholarly discourses on novelty and innovation, raising issues that relate to media change itself, rather than the life cycles of specific technologies. In the field of media studies, questions concerning how to define the complementary notions of "oldness" and "newness", and its implications for how we conceive both change and continuity across media history, have been addressed from several perspectives and discussed in a huge number of publications, whose examination is beyond the scope of this limited contribution. ${ }^{48}$

One of the main results of the debate on the persistence or resurgence of our socio-technical past has been the abandoning of a series of dichotomies based on the biographical age and technological features of media, such as old vs. new, analogue vs. digital, as well as the binary distinction between analogue/old vs. digital/new, which had problematically characterized certain descriptions of technological change. Accordingly, scholarly attention has been increasingly drawn to the renewability of media over time, addressed by concepts like those of "residual media," 49 "media hysteresis," 50 and the "double birth" of media. ${ }^{51}$

Moving forward into the analysis of the re-appropriation and re-invention of "old" media technologies, increasingly addressed as part of a continuous process of mutual construction of "new" and "old" media, scholars emphasized the role of popular and personal narratives through which media from the past becomes meaningful again and are hence renewed. ${ }^{52}$ Yet, the technological features of media and their physical circulation, as well as their obsolescence, still prove to have an influence on this process. This is exemplified, for example, by the phenomenon of "technological resistance," which refers to cases where the users re-appropriate old technologies, due to their features and obsolescence, with the aim of contrasting the diffusion of new, dominant artefacts. ${ }^{53}$ Another example, related to the global circulation of obsolete technical artefacts, is that of "creole technologies," 54 that is, "old" technologies from the rich world which are no longer in use in the originating territory but keep circulating in the poor world, where they come to be combined in original ways with local technologies. Hence, new interpretative frameworks have been proposed,

43 Sergio Minniti, 'Polaroid 2.0. Photo-objects and Analogue Instant Photography in the Digital Age,' Tecnoscienza: Italian Journal of Science and Technology Studies, 7, 1, 2016, 17-44.

44 Helen Stuckey and Melanie Swalwell, 'Retro-Computing Community Sites and the Museum,' in Marios C. Angelides and Harry Agius, eds, Handbook of Digital Games, John Wiley \& Sons, 2014, 523-547.

45 Claes Thorén, Mats Edenius, Jenny Eriksson Lundström and Andreas Kitzmann, 'The Hipster's Dilemma: What is Analogue or Digital in the Post-digital Society?,' Convergence: The International Journal of Research into New Media Technologies, 25, 2, $2019,324-339$.

46 Paolo Magaudda and Sergio Minniti, 'Retromedia-in-practice: A Practice Theory Approach for Rethinking Old and New Media Technologies,' Convergence: The International Journal of Research into New Media Technologies, 2019, https://journals.sagepub.com/doi/ full/10.1177/1354856519842805

47 David Sarpong, Shi Dong and Gloria Appiah, 'Vinyl Never Say Die': The Re-incarnation, Adoption and Diffusion of Retro-technologies,' Technological Forecasting and Social Change, 103, 2016, 109-118.

48 For a recent critical review, see Simone Natale, 'There Are No Old Media,' Journal of Communication, 66, 4, 2016 , 585-603.

49 Charles R. Acland, ed, Residual Media, University of Minnesota Press, 2007.

50 Philippe Theophanidis and Ghislain Thibault, 'Media Hysteresis: Persistence through Change,' Alphaville: Journal of Film and Screen Media, 12, 2016, 8-23.

51 We refer here to the extended version of the notion, as it is discussed in André Gaudreault and Philippe Marion, 'Measuring the 'Double Birth' Model against the Digital Age,' Early Popular Visual Culture, 11, 2, 2013, 158-177.

52 Simone Natale, 'There Are No Old Media'

53 Cfr. Sergio Minniti, 'Polaroid 2.0'; Christine Lindsay, 'From the Shadows: Users as Designers, Producers, Marketers, Distributors, and Technical Support,' in Nelly Oudshoorn and Trevor Pinch, eds, How Users Matter: The Co-construction of Users and Technology, MIT Press, 2003, pp. 29-50.

54 David Edgerton, 'Creole Technologies and Global Histories: Rethinking how Things Travel in Space and Time,' Journal of History of Science and Technology, 1, 2007, 75-112. 
which keep together the symbolic dimension of media, where change-related narratives are constructed, with their material and performative dimensions. ${ }^{55}$

In the field of Television Studies, similar reflections on the artificial boundaries between the "old" and the "new", and on the need to study processes of technological obsolescence and renewal, have been increasingly advanced in recent years. These points have been addressed, for example, by Lisa Parks, who pointed her attention to "the accumulation of used media hardware that has emerged since the dawn of television and has greatly accelerated with the growth of the global digital economy" to problematize the "reductive bifurcations of 'old' and 'new' media." ${ }^{6}$ As pointed out by Parks, processes of obsolescence such as those fostered by the analogue switch-off (ASO) - i.e. the switch from analogue to digital TV signal, "catalyse" different ways of thinking about what television is and how we might research it. To cope with these challenges, she suggests scholars should expand their scope to analyse the material production and circulation of technology, studying "TV and computer manufacturing, the global trade of receivers, electronics disposal, and marketing for new technology, among other things." ${ }^{7}$ A similar argument has been advanced by Vicki Mayer and Clare Cannon, who stressed the need to study television manufacturing, disposal, and recycling as "a corrective to the underlying assumptions about media's value in television studies today." 58

Indeed, the growing awareness among scholars that the study of television should include a longer history of the medium and its life cycles as a material object reflects a more general, increasing interest in taking into account the material production, circulation, disposal, and renewal of technology through which (multiple) media identities continuously unfold. On the one hand, from this derives a focus on the issues raised by the huge circulation of electronic waste (e-waste) and the predisposition of technology for future decomposition ("Literally speaking, e-waste is the future of communications ... as communications scholars, we must also engage with waste management literature and practices if we take the future of communications seriously"). ${ }^{59}$ On the other hand, it also opens up for new understandings of the "creative renewal of trash" which, far from being just and end-product of technological development, might become a resource "to be recovered and revalorized, through recycling and reuse," 60 and hence a source of innovation such as in the cases of the "creole technologies" analysed by David Edgerton. ${ }^{61}$

\subsection{Implementing Low Cost Digital Libraries for Rural Communities by Re-Functioning Obsolescent Television Sets}

The idea of creating Offline-pedia originally came from the challenges posed by both the digital divide and the obsolescence of analogue television in Ecuador. Due to Ecuador's switch from analogue to a digital broadcasting signal, which will progressively take place between 2020 and 2023, ${ }^{62}$ thousands of old TV sets and other

55 See e.g. Paolo Magaudda and Sergio Minniti, 'Retromedia-in-practice.'

56 Lisa Parks, 'Falling Apart: Electronics Salvaging and the Global Media Economy,' in Charles R. Acland, ed, Residual Media, University of Minnesota Press, 2007, pp. 32-47.

57 Lisa Parks, 'My Media Studies: Thoughts from Lisa Parks,' Television \& New Media, 10, 1, 2009, $126-127$.

58 Vicki Mayer and Clare Cannon, 'A Greener Screening Future: Manufacturing and Recycling as the Subjects of Television Studies,' in Manuel Alvarado, Milly Buonanno, Herman Gray and Toby Miller, eds, The SAGE Handbook of Television Studies, SAGE, 2014, p. 196.

59 Sabine LeBel, 'Wasting the Future: The Technological Sublime, Communications Technologies, and E-waste,' communication+1, 1, 1, 2012, https://scholarworks.umass.edu/cpo/vol1/iss1/7; see also Jennifer Gabrys, Digital Rubbish: A Natural History of Electronics, University of Michigan Press, 2011.

60 Karma Chahine, 'Mobilising Creativity: Trash and Sydney’s Garage Sale Trail,' Wi: Journal of Mobile Media, 10, 1, 2016, http://wi.mobilities.ca/ mobilising-creativity-trash-and-sydneys-garage-sale-trail/

61 David Edgerton, 'Creole Technologies and Global Histories.'

62 Metro Ecuador, 'Apagón analógico: Hasta el 2023 deberás tener un televisor digital o un decodificador en tu hogar,' Metroecuador.com, 22 September 2018, https://www.metroecuador.com.ec/ec/noticias/2018/09/22/apagon-analogico-2023-deberas-televisor-digital-decodificadorla-television-hogar.html 
S. Minniti et al., Implementing Low Cost Digital Libraries for Rural Communities by Re-functioning Obsolescent Television Sets

complementary technologies will become obsolete. One of the questions we want to address through the development of our project is how artefacts from television's material heritage can be transformed into new technologies, instead of becoming e-waste or relics from the past. The basic idea is that of "re-functioning" old television equipment by transforming them into hybrid analogue-digital devices that provide disadvantaged communities with access to digital information resources.

As discussed in the previous section, processes of obsolescence such as those fostered by the analogue switch-off (ASO) raise issues relating to e-waste and the consequences of its accumulation and dismantling, and opportunities to transform this waste into useful resources. In particular, the obsolescence of display technologies based on cathode ray tubes (CRT), such as old computer monitors and televisions, presents a challenge owing to the high lead content embedded in the funnel and neck sections of the CRT glass. As a consequence, disposal in landfills and open dumping leads to the large-scale contamination of the environment. Avoiding contamination therefore requires the adoption of environmentally friendly management practices for end-of-life CRT glass. ${ }^{63}$

Within the European Union (EU), a number of policies and legislations have been developed to cope with the environmental issues raised by the obsolescence of CRTs and, more generally, by the treatment of e-waste. They are based on the principle of extended producer responsibility (EPR), which requires manufacturers to adopt an environmental approach to design and assess the environmental impact of their products. ${ }^{64}$ Based on the EPR concept, the EU issued a series of Directives, such as the 2002/96/EC ${ }^{65}$ and 2003/108/EC ${ }^{66}$ Directives on the disposal of waste electrical and electronic equipment (WEEE), which require producers of CRTs to meet mandatory recycling targets. Moreover, CRTs are specifically listed in the United Nation's Basel Convention on the Control of Transboundary Movement of Hazardous Wastes and Their Disposal (1989), ${ }^{67}$ which aims at preventing the transfer of hazardous wastes from developed to less developed countries.

By contrast, in Latin America and the Caribbean, there are no regional laws and most countries have not adopted national policies related to the treatment of e-waste. To solve this issue, the United Nations Industrial Development Organization (UNIDO) launched an initiative in 2018 which will provide policy advice to 13 Latin American countries to help them develop legislations on the proper disposal and recycling of e-waste. ${ }^{68}$ Among the countries involved we find Ecuador, where no national policies related to the treatment of e-waste have been developed yet. Though some local governments have already made progress in this area, and there are private initiatives by mobile companies regarding the recycling of mobile phones, e-waste is being deposited in municipal landfills and mixed with normal trash, causing public health issues. ${ }^{69}$ Hence, Ecuador's ASO is expected to increase the amount of e-waste deriving from the massive disposal of CRT TVs, as it already happened in Mexico, the first Latin American country to complete ASO, and is expected to happen in other Latin American countries where the ASO is currently being carried out, such as Peru. ${ }^{70}$

63 Paschal O. Iniaghe and Gilbert U. Adie, 'Management Practices for End-of-life Cathode Ray Tube Glass: Review of Advances in Recycling and Best Available Technologies,' Waste Management \& Research, 33, 11, 2015, 947-961.

64 Martin Goosey, 'End-of-life Electronics Legislation: An Industry Perspective,' Circuit World, 30, 2004, 41-45.

65 European Union, 'Directive 2002/96/EC of the European Parliament and of the Council of 27 January 2003 on Waste Electrical and Electronic Equipment (WEEE),' Official Journal of the European Union, L 37, 2003, 24-38.

66 European Union, 'Directive 2003/108/EC of the European Parliament and of the Council of the European Community, 8 December 2003 Amending Directive 2002/96/EC on Waste Electrical and Electronic Equipment (WEEE),' Official Journal of the European Union, L 345, 2003, 106-107.

67 UNEP, Basel Convention on the Control of Transboundary Movement of Hazardous Wastes and Their Disposal, UNEP-Basel Convention, 1989. 68 UNIDO, 'Solving the e-waste problem in Latin America.' https://www.unido.org/news/solving-e-waste-problem-latin-america 69 Hugo Carrión, 'Ecuador,', in Alan Finlay, Global Information Society Watch 2010: Focus on ICTs and Environmental Sustainability, APC and Hivos, 126-128. https://giswatch.org/sites/default/files/gisw2010countryecuador_en.pdf

70 Marco Gusukuma and Ramzy Kahhat, 'Electronic Waste after a Digital TV Transition: Material Flows and Stocks,' Resources, Conservation \& Recycling, 138, 2018, 142-150. 


\subsubsection{Conceptual Description: Designing Rural Digital Libraries as a Form of Cosmolocalist Critical Technical Practice}

The Offline-pedia project addresses two interrelated issues: on the one hand, it aims at solving the problem of accessing information in the absence of fully developed ICT infrastructures, as is the case of Ecuadorian rural communities; on the other hand, it does so by "re-functioning" the television equipment that will become obsolete due to Ecuador's ASO. From a conceptual point of view, it adopts the "critical technical practice" perspective ${ }^{71}$ according to which engineering practices should critically address societal issues and propose alternative configurations of technology that redistribute power within society.

In our project, this principle is declined in two ways: first, Offline-pedia reconfigures Wikipedia and other digital information resources by separating information from its main distribution media, and by "re-materializing" it through a physical device that makes digital information accessible without any connection to the Internet. In this respect, the project takes into account the evolution of DLs from Internet-based to stand-alone devices discussed previously, adopting the latter solution to make digital information available to the rural communities of Ecuador. Though Offlinepedia is a DL including a number of different collections, its name refers specifically to Wikipedia, since Wikipedia is considered emblematic of the principle of universal access to information ("free access to the sum of all human knowledge" by "every single person" in the words of Jimmy Wales, co-founder of Wikipedia), ${ }^{72}$ yet this perspective is First-World-centric and does not consider how access to information is limited by the digital divide affecting developing countries. ${ }^{73}$ By referring to Wikipedia, the name chosen thus reflects our intention to cope with the limits of such "universally accessible" platforms for the benefit of disadvantaged communities.

Second, the project reconfigures the status of artefacts from television's material heritage from obsolescent materials and future e-waste to useful resources, and from old to new technologies, by proposing a possible, creative way to reverse their apparently inevitable obsolescence. In this respect, Offline-pedia reflects both the contemporary debate on the obsolescence and renewability of media and the concern among media scholars for considering the ecological dimension of technology. ${ }^{74}$ Since the project is currently self-funded and carried out by a narrow group of volunteers, its impact is clearly too limited to be effective regarding the upcycling of e-waste into new technologies. Nonetheless, it represents an example of how media scholars might engage with the issue of e-waste in an active and critical manner.

This limitation also points to an additional theoretical argument. To improve the potential effectiveness of Offline-pedia, we combined the "critical technical practice" perspective with a "cosmolocalist" approach to innovation, commonly summarized by the motto "design global, manufacture local" (DG-ML).$^{75}$ According to "cosmolocalist" theorists, technology should not be considered as a commodity but rather as a commons, like natural gifts such as air and water. To achieve this status, technology's design should be community-oriented, and refined through participative processes; and it should be liberated from the dominance of strict intellectual property rights, so as to be shared freely on a global scale, while at the same time it should be produced locally in the so-called "microfactories," such as the FabLabs and Makerspaces, with local materials, to foster an environmental-friendly relocalization of manufacturing.

Accordingly, Offline-pedia embodies the "cosmolocalist" approach by proposing a community-oriented device that can be considered as a commons: it is designed to fulfil the needs of rural communities with limited access to the Internet, and can be implemented according to the specific needs of such communities; it can be produced locally in any FabLab and with local materials, by recycling obsolescent artefacts that would otherwise become e-waste; it uses

71 Philip E. Agre, 'Toward a Critical Technical Practice: Lessons Learned in Trying to Reform Al,' in Geoffrey C. Bowker, Susan Leigh Star, William Turner and Les Gasser, eds, Social Science, Technical Systems, and Cooperative Work: Beyond the Great Divide, Erlbaum, 1997, pp.131-157.

72 Jimmy Wales, 'Foreword,' in Andrew Lih, The Wikipedia Revolution: How a Bunch of Nobodies Created the World's Greatest Encyclopedia, Hyperion, 2009, p. xii.

73 Morten Rask, 'The Reach and Richness of Wikipedia: Is Wikinomics only for Rich Countries?,' First Monday, 13, 6, 2008, https://journals.uic. edu/ojs/index.php/fm/article/view/2046/1970

74 Richard Maxwell and Toby Miller, 'Ecological Ethics and Media Technology,' International Journal of Communication, 2, $2008,331-353$.

75 Vasilis Kostakis, Vasilis Niaros, George Dafermos and Michel Bauwens, 'Design Global, Manufacture Local: Exploring the Contours of an Emerging Productive Model,' Futures, 73, 2015, 126-135. 
S. Minniti et al., Implementing Low Cost Digital Libraries for Rural Communities by Re-functioning Obsolescent Television Sets

open hardware and software and is released under a Creative Commons license, thus fostering a culture of sharing that makes technology replicable and improvable by any interested community on a global scale.

\subsubsection{Technical Description}

From a technical point of view, Offline-pedia includes the following hardware components:

- an old analogue TV set, used as a monitor display;

- a Raspberry $\mathrm{Pi},{ }^{76}$ which is a low-cost, credit card-sized, "open" mini-computer;

- a frequency modulator, which converts the digital signal into analogue;

- a microSD card, which contains the software and databases;

- an RCA cable and a TV antenna cable;

- a keyboard;

- a mouse device.

This configuration makes the device inexpensive (around 100\$). To create the first prototype we recycled several components, including the TV set, frequency modulator, keyboard, and mouse device. We also used recycled wood to create the box containing all the hardware parts. The box has been 3D modelled by using the free version of Onshape, ${ }^{77}$ a computer-aided design (CAD) software system, and then laser cut at the Yachay FabLab, ${ }^{78}$ a Digital Fabrication Laboratory located in San Miguel de Urcuquí, in the Ecuadorian province of Imbabura (Figure 2). The design of the box was made simple by designing lego-like pieces which enable a quick and easy assembling without the need of extra tools such as screwdrivers. The wooden box was designed to hide and secure the components and cables, but at the same time it was conceived to create a one-piece device perceivable as a terminal with its own technological identity.

The maintenance of the device is provided by the project's volunteers (undergraduate students from our institution), who visit the installation places around every three months. It is also important to emphasize that the leaders of the communities where Offline-pedia is installed receive extra training on how to use and preserve the device and they keep in constant communication with the project team.
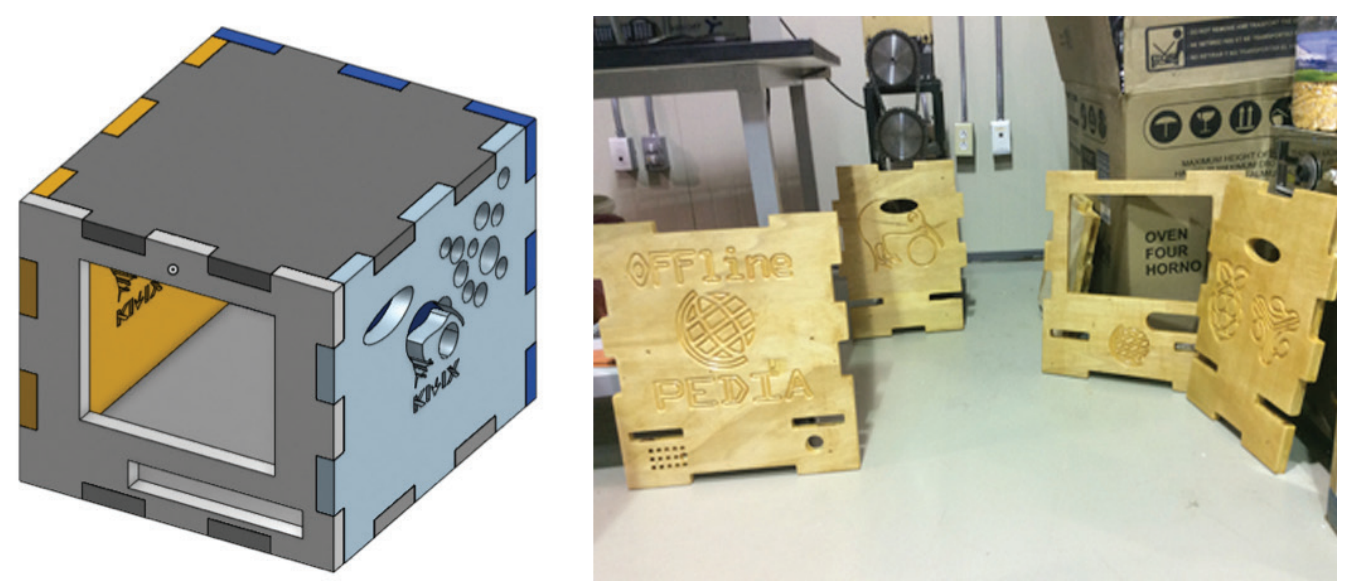

Figure 2. The Offline-pedia box during the 3D modelling phase (left), and once laser cut from recycled wood and ready to be assembled (right). Photos by the authors. 
The software part of the device includes only free and open software, in order to make Offline-pedia as reproducible and accessible as possible. The operating system loaded into the Raspberry $\mathrm{Pi}$ is Raspbian, ${ }^{79}$ a free operating system based on Debian and optimized for the Raspberry Pi hardware. The additional software package, which lets us compress Wikipedia and the other databases and store them into a single microSD card, is called Kiwix. Kiwix is a free software package that allows downloading and accessing various Wikimedia Projects, ${ }^{80}$ including Wikipedia. As stated by its website, Kiwix has been specifically designed to "bring internet content to people without internet access." ${ }^{81}$ New Kiwix packages are updated every six months and are freely available to download from the organization web page..$^{82}$ As in the case of hardware maintenance, the software is updated by the project volunteers during their visits to the installation sites.

Included in the release installed into our device are the full Wikipedia database in Spanish, a basic version of the Wikipedia database in English, other Wikimedia projects such as Wiktionary ${ }^{83}$ and Wikiquote, ${ }^{84}$ and two e-books repositories, Wikibooks ${ }^{85}$ and Project Gutenberg, ${ }^{86}$ which include a total of around 16,000 e-books in the public domain. Since half the installations of Offline-pedia were located within public schools, of particular importance is Wikibooks, a powerful tool for pedagogical purposes which contains free, printable, high-quality textbooks that can be used in the classroom and for self-education. Although most are educational, the e-books also cover a wide range of other topics, including gastronomy, sports, religion, interpersonal relationships and even a guide to Harry Potter novels. Compared to Wikipedia articles, Wikibooks textbooks are more structured and expand on the information in a more narrative manner, making self-education more entertaining, also through the inclusion of multimedia content. ${ }^{87}$

Figure 3 shows the main menu of the device, from which the different databases can be accessed, and an example of how e-books are visualized. Besides allowing the users to read e-books on screen, Offline-pedia also provides them with the possibility of downloading the requested content via Wi-Fi, since the Raspberry Pi has a Wi-Fi module that can be connected to any mobile device, without the presence of an Internet connection. The search interface is very simple. The commands are reduced to just: search, read, load, and download. In the e-books section, a menu allows users to browse the library, load random documents, and go back to the homepage. While at the beginning the commands and menu were in English, in the last updates the language of the interface has been switched to Spanish. 

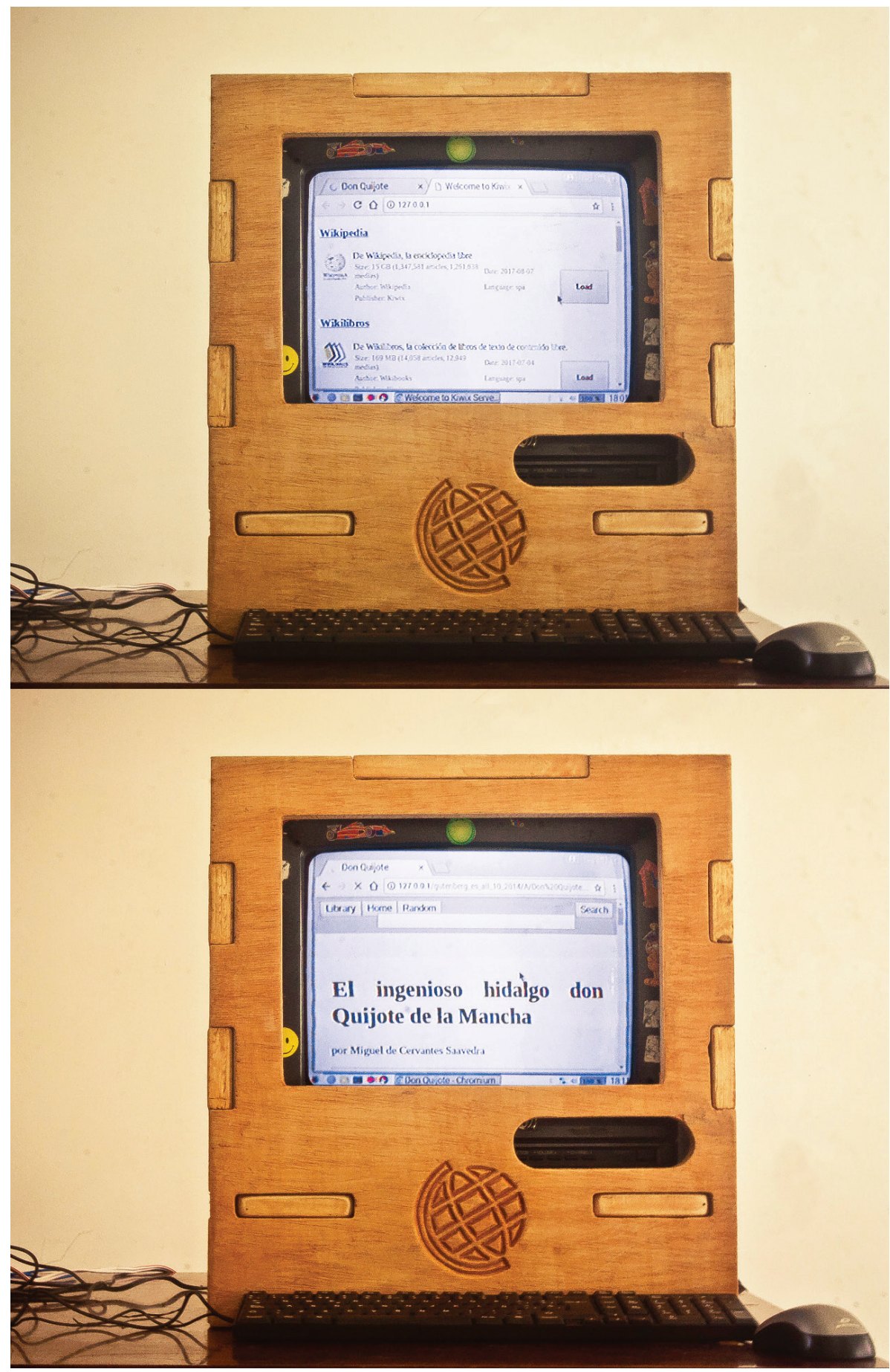

Figure 3. The main menu of Offline-pedia, from which the collections can be accessed (above), and an example of how e-books are visualized on screen (below). Photos by the authors.

\subsubsection{Current Status and Future Implementations}

To date, four Offline-pedia DLs have been installed within Ecuadorian rural communities. Two of them have been installed at the public meeting rooms (casas comunales) of the communities, one in Cajas Jurídica, located in the Ecuadorian province of Imbabura, and another one in Barrio "Progreso," Cantón de Pacto, in 
the province of Pichincha. The other two devices have been installed at the public schools of the communities "La Concepción," Cantón Mira, in the Carchi province, and "San Virgilio," Cantón Puyo, in the province of Pastaza.

Since poor digital literacy is a major problem in such rural contexts, and in developing countries in general, training remains a key to the adoption and use of DLs. ${ }^{88}$ To cope with this issue, introductory tutorials on how to use the device, and on the content included, were given to the communities during the installations of Offline-pedia (Figure 4). Yet, the training was basic and one-off, since our project underwrites the concept of Minimally Invasive Education (MIE), which has been developed by Sugata Mitra, a computer scientist of the National Institute for Information Technology (NIIT) in India, and adopted by numerous projects related to DLs and information kiosks in developing countries. ${ }^{89}$ MIE is a technique used to increase digital literacy which consists of installing digital devices in marginalized communities with minimal or no training, in order to stimulate self-discovery, allow community members to learn by themselves how to interact with the devices, and educate each other. As reported by the literature, the unsupervised use of digital devices, grounded on people's inherent cognitive ability to teach themselves, can lead to accelerated learning of skills and the rapid improvement of digital literacy.

Clearly, assessing the reaction of the intended audience and the extent to which community members concretely self-educate by both using Offline-pedia and accessing the information contained within it requires a user study, which still needs to be carried out. Such study will be conducted in the near future by carrying out semi-structured interviews to the users. We expect that the analysis of use in the two different settings chosen, the community meeting room and the public school, and of the reception of the different collections included, might provide us with useful insights on a variety of potential uses of Offline-pedia by the members and students of Ecuadorian rural communities. Through the user study, we also aim at improving the device and making it as consistent as possible with the specific needs of the communities involved.

To date, we received overall positive feedbacks during the installations and visits, through which we started to identify different uses and needs. For example, we acknowledged that children have some difficulty in turning on the device, which they solve by themselves and with the help of their friends. In general, children reported that they always use it in groups. They expressed also the need to include more audio-visual content, of which Wikipedia and other collections are poor, and even videogames. On the other hand, they demonstrated much curiosity and reported searches on a variety of subjects, mainly related to their environment and the topics addressed at school ("toads, snakes, and other animals," "cows, volcanoes, dinosaurs, and other animals," "the bark of trees," "the stars and the universe," "the Earth and the countries of the world"). Differently, adults showed more interest in the Wikibooks collection, within which they searched for textbooks to improve their agriculture techniques, and information related to harvesting such as the moon phases, sowing seasons, etc. Adults also underlined the usefulness of the device to their children, since it allows them to fulfil their school requirements without having to go to the nearest town to find a cyber-café with Internet connection.

88 Gobinda G. Chowdhury, 'Digital Divide.'

89 Sugata Mitra, The Hole in the Wall: Self-Organising Systems in Education, Tata-McGraw-Hill, 2006. The MIE approach has been adopted by the Digital Doorway project, see a2004dings Doorway: dge, adopted by the Digital Doorway projectrian rural communities.n sites.a anche versatile, con .to all'cKim Gush and Ruth de Villiers, 'Application Usage of Unsupervised Digital Doorway Computer Kiosks in Remote Locations in South Africa,' Proceedings of the Annual Research Conference of the South African Institute of Computer Scientists and Information Technologists (SAICSIT 10), ACM, 2010, 93-103. Other projects not discussed in this paper have been also based on MIE, see for example Hannah Slay, Peter Wentworth and Jonathon Locke, 'BingBee, an Information Kiosk for Social Enablement in Marginalized Communities,' in Proceedings of the Annual Research Conference of the South African Institute of Computer Scientists and Information Technologists (SAICSIT 06), ACM, 2006, 107-116. 


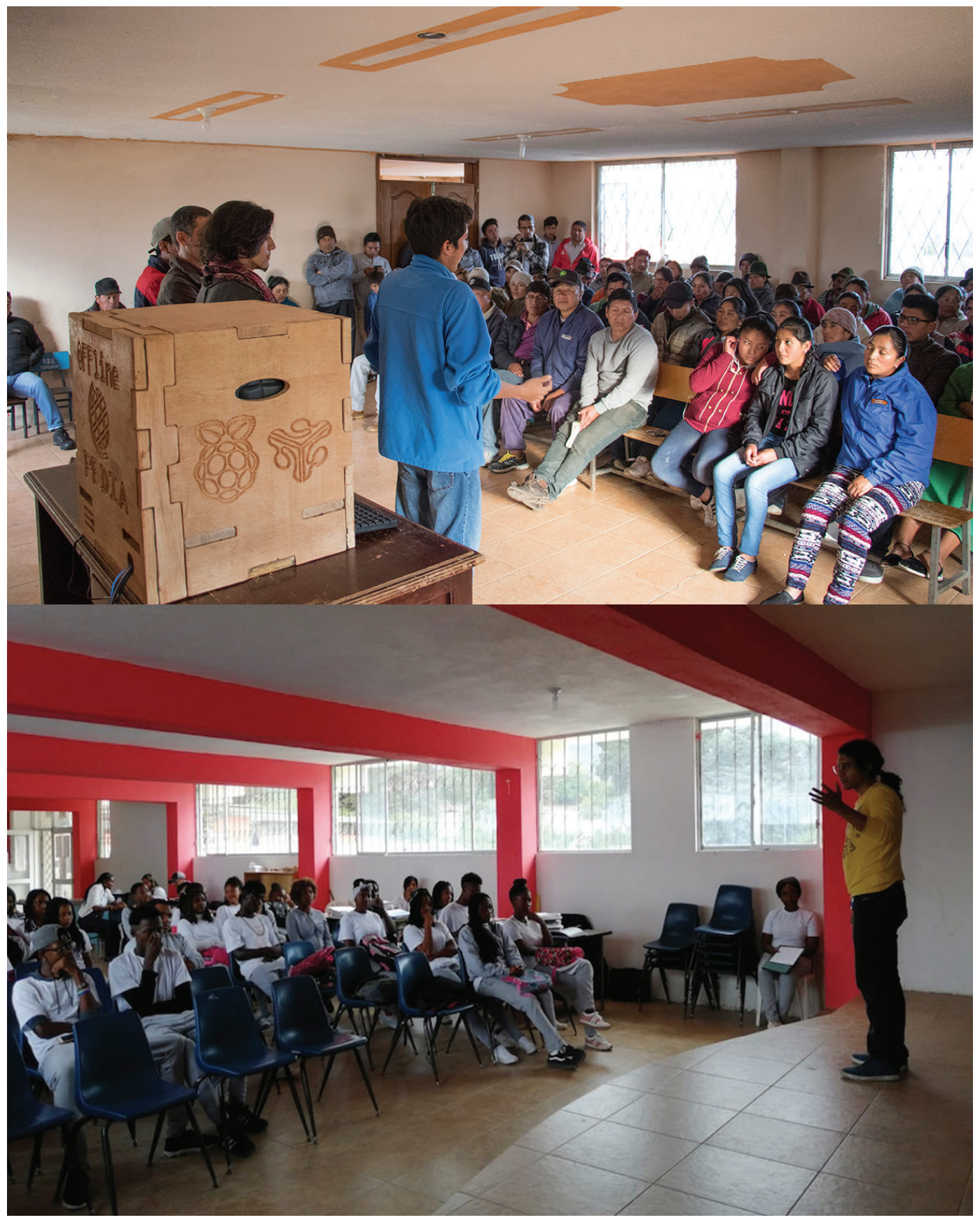

Figure 4. Volunteers illustrating the functioning of Offline-pedia to the rural community of Cajas, located in the Ecuadorian province of Imbabura (above), and to the students of the community of "La Concepción," in the Ecuadorian province of Carchi (below). Photo by the authors.

\section{Conclusions}

The digital divide is still affecting several developing and emerging countries, such as Ecuador. In this article, we addressed the issue of a digital divide by illustrating an ongoing project we are carrying out, named Offline-pedia, which focuses on the "re-functioning" of obsolescent television equipment to create digital libraries capable of 
providing access to digital collections of information in contexts where access to the Internet is limited or unavailable. A complementary issue addressed was that of how obsolescent technologies can be renewed and transformed into useful resources instead of becoming e-waste.

In designing the project, we drew upon previous experiences highlighting the potential benefits of rural digital libraries, as well as on the reflections of media scholars relating to the obsolescence and renewal of technology, which express an increasing concern about the ecological dimension of media. Yet, to assess the actual efficacy of our project, further research on how the rural communities involved engage with Offline-pedia has to be carried out through a proper user study, which we plan to conduct in the near future. With respect to the issue of the e-waste produced by Ecuador's analogue switch-off, the main limitation of the project is represented by its small scale, which prevents Offline-pedia from having a significant impact. Nonetheless, we hope that the project might represent an example of how scholars might actively engage with relevant societal issues, such as the digital divide and the problem of e-waste, by combining social theories with technical practices, as it is suggested by the "critical technical practice" approach.

\section{Acknow ledgements}

Whilst the article has been collaboratively discussed and organised, in compliance with Italian academic folkways, the authors acknowledge that Sergio Minniti wrote sections 1, 3, 3.1, 3.2, 3.3, 3.3.1, and 4; Sergio Minniti and Joshua Salazar jointly wrote sections 3.3.2 and 3.3.3; Sergio Minniti and Jorge Vega jointly wrote section 2. The authors also want to thank Gerardo Acosta from Yachay FabLab for his help with the prototyping, and students Juan Diego Pillajo, Jenner Feijó, and Bryan Inlago for their volunteering in the project.

\section{B i ographies}

Sergio Minniti is a postdoctoral researcher in Sociology at the University of Padova (Italy). He holds a PhD in Sociology of Communication and New Media from the IULM University of Milan (Italy). He researches in the areas of Science \& Technology Studies (STS) and Media Studies.

Joshua Salazar is an undergraduate Physics student, free software activist, and creator of the Offline-pedia project. His research focuses on the application of supercomputing to Material Science. Among his extracurricular activities are: divulging the importance of science and math education to rural communities, and working on the Offline-pedia project for providing access to digital information to disadvantaged communities.

Jorge Vega is an undergraduate Physics student. He researches in Computational Physics, specifically in the simulations of materials, e.g. simulating the "universe of the small" with Density Functional Theory. He belongs to the research group CompNano, which develops simulations of oxides and graphene. He has also been working on various projects to divulge science to Ecuadorian rural communities. 